\title{
Infantile hypertrophic cardiomyopathy due to MRPL44 deficiency
}

INSERM

\section{Source}

INSERM. (1999). Orphanet: an online rare disease and orphan drug data base. Infantile hypertrophic cardiomyopathy due to MRPL44 deficiency. ORPHA:352563

Infantile hypertrophic cardiomyopathy due to MRPL44 deficiency is a rare mitochondrial oxidative phosphorylation disorder with complex I and IV deficiency characterized by hypertrophic cardiomyopathy, hepatic steatosis with elevated liver transaminases, exercise intolerance and muscle weakness. Neuro-opthalmological features (hemiplegic migraine, Leigh-like lesions on brain MRI, pigmentary retinopathy) have been reported later in life. 